\title{
The Zelenograd Center of Microelectronics
}

\author{
B.M. Malashevich ${ }^{1}$ and D.B. Malashevich ${ }^{2}$ \\ ${ }^{1}$ JSC “Angstrem \\ mbmeangstrem.ru \\ ${ }^{2}$ National Research University, Moscow Institute of Electronic Technology (MIET) \\ denis@malashevich.ru
}

\begin{abstract}
This article deals with appearance of microelectronics in the USSR and establishing of its innovation centre in Zelenograd, Moscow. Prerequisites for creation of the microelectronics, measures on the development of the scientific-research centre are considered and the acting persons presented. Structure of the centre is described as a complex research and development corporation with complete set of functions. Its enterprises are displayed as well as their specialization and their first achievements. The technical level of the microelectronics centre production released in the first years of work is evaluated as corresponding to the world's manufacturing level; however, some reasons for lagging behind world leaders, beginning in the following period, are also mentioned.
\end{abstract}

Keywords: Centre of microelectronics, Zelenograd, (miniature) radio-set "Micro", IC, “Tropa".

\section{Introduction}

During the last half of the last century, the technology of assembly of the radioelectronic equipment (REE) from discrete elements has settled the possibility. The world had come to the sharpest REE crisis and radical measures were required. In the USSR the electronic industry was an independent branch of the State Committee on electronic techniques (abbreviated GKET in Russian), then transformed the Ministry of electronic industry (MEP), under the ministry of A.I. Shokin.

\section{Preconditions}

By this time and in the USSR and abroad, preconditions were already ripened for the creation of semiconductors and hybrid integrated circuits (IC). Integrated technology had been industrially mastered for semiconductor transistors, thick-film, and thin-film ceramic printed circuit-boards. The question was only: which one would be the first will be lit up with a pleasant IC idea. The first that appeared were Jack Kilby from Texas Instruments (TI) and Robert Noyce from Fairchild Semiconductor in the USA. In 1958, they had made the first IC: J. Kilby on germanium and R. Noyce on silicon. Juri Osokin of the Riga Plant of Semiconductor Instrumentation was the third one to begin production and supplies of the semiconductors ICs "R12-2" in 1962 (Figure 1). 
Simultaneously with them appeared a hybrid IC. Both American and our experts predicted the most intensive development of the hybrid ICs, however, claiming that semiconductor ICs would dominate the market only by 1980 .

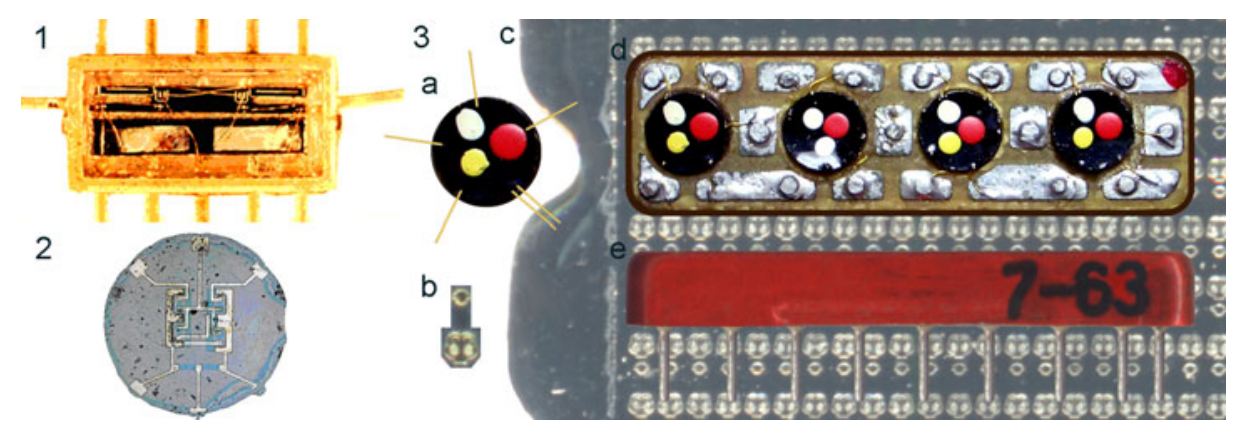

Fig. 1. The three first ICs: of Jack Kilby, of Robert Neuse, and of Juri Osokin (an IC crystal with a germanium plate fragment in the background)

Using germanium for ICs was not promising. It has quickly understood both at TI and at Pulsar that the direction was toward silicon. Between 1959 and 1960, they began to work at Pulsar on creation of planar technology of silicon devices. By the end of 1961 at Pulsar, they generated a department of microelectronics whose chief was B.V. Malin.

\section{Trailblazers}

In the USSR, they formed two groups of trailblazers in the Soviet microelectronics: at GKET and at NPO "Almaz" (then "KB-1"). Since first half of the 1950s the Almaz chief engineer F.V. Lukin had organized active works on microminiaturization REE on the then available element base. However, by the end of 1950s, it became clear, that more radical methods were needed. Here then F.V. Lukin also had charged A.A. Kolosov to one of the most active, competent and interested in the decision of this problem of specialists in the Almaz. They freely knew three foreign languages thoroughly to study approaches to microminiaturization on foreign and domestic sources.

The results of this work were generalized in 1960 in A.A. Kolosov's small monographic called Questions of Microelectronics, which became the textbook for many specialists. In this work, the author has perfectly proved the necessity and timeliness of the beginning of large-scale works on research of the problems connected with the creation of integrated circuits; he stated new principles of REE creation. In 1960, F.V. Lukin had charged A.A. Kolosov to create the very first laboratory in the USSR on microelectronics. The laboratory started active work involving numerous scientific research institutes and universities as counterparts. Ideas of microelectronics had started to expand in the country. So, the non-suspecting F.V. Lukin, had started to prepare for a theoretical reserve and a staff for the Center of 
microelectronics in Zelenograd, which would be established in three years. See Figure 2 for a partial view of the center.

During the same period, A.I. Shokin's assembled a group of specialists at Pulsar and GKET to seek ways of generating output from the REE crisis. He had already concluded about the necessity of the creation and development of a new branch sector microelectronics. The branch sector, (i.e. systems of scientific research institutes (abbreviated NII in Russian), would design offices (KB), and develop skilled and serial factories distributed all over the country; they would solve all special problems on the creation and duplication of products of

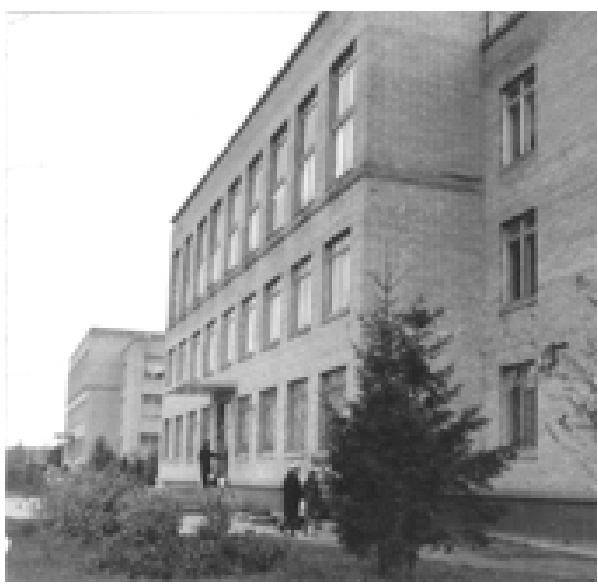

Fig. 2. Two of three buildings, from its beginning; Soviet Center of Microelectronics in Zelenograd microelectronics. In 1959 he directed specialists to the USA to train and study planar silicon technology. When A.A. Kolosov had addressed K.I. Martjushchov's deputy, A.I. Shokin, with the results of the works and the offer on microelectronics, he received full understanding. At once, he had estimated the initiative and had suggested to organize a conference to gather the necessary heads. Such conference took place in the end 1961 in Leningrad under K.I. Martjushov's presidency. With the basic report A.A. Kolosov, with the supporting report on systems of memory, F.G. Staros, director SKB-2 in Leningrad, acted. Then A.A. Kolosov and K.I. Martjushov invited A.I. Shokin to discuss the problem, they came to the conclusion about the necessity of the creation of the uniform Center of microelectronics (CM).

The CM idea consisted in the formation of an innovative center for microelectronics. It would be locally placed functionally with a full complex of scientific research institutes with the experimental plants, solving all specific problems of creation and application of IC. For CM special materials, it should develop the technological, control, and measuring equipment for direct IC, based on REE. All this should be fulfilled on experimental plants and be transferred for mass duplicating to serial factories. In the USSR, they were already able to create the research-and-production centers and A.I. Shokin had the relevant experience.

\section{The Decree}

$\mathrm{CM}$ allocation had to be small and independent; the location city should be close to Moscow and it should create a scientific research institute and experimental plants. They found the place for such a city. In 1958, the Krjukovo railway station near Moscow was ideal for light industry construction of the "Sputnik" settlement (it has received the name «Zelenograd» in 1963). 
By this time, there were obvious disproportions: provision for mass habitation was under construction and practically nothing had been made on the industrial building. However, expansion of works on creation CM needed the decree of the Central Committee of the CPSU and SM of the USSR; its output needed the consent of the first secretary of the Central Committee of the CPSU and chairman of SM of the USSR, N.S. Khrushchev. A.I. Shokin had begun preparations. The main base for preparation for the Decree the CM creation and all accompanying documents, posters, and exhibits became Pulsar. Supervising the preparation was V.N. Malin (chief of the general department of the central committee of the CPSU), I.D. Serbin (chief of the defensive department of the central committee of the CPSU), and L.V. Smirnov (chairman of the military-industrial commission).

In the beginning of 1962, A.I. Shokin had achieved N.S. Krushchev's consent to carry out a small exhibition with a report during a break of session of presidium of the central committee of the CPSU. Hence, N.S. Khrushchev had already apprehended the idea and straight off did not reject it. Action took place, and N.S. Khrushchev had agreed on the further consideration of the offer. It has not simply agreed, but, similarly, had allocated for itself the problem of microelectronics and it was important for the nation.

Soon, in March of 1962, at the annual viewing of the architectural projects in Red hall of Mossoviet, they reported about serious disproportions in building of "Sputnik", N.S. Khrushchev said:

\section{"It is necessary to discuss about microelectronics".}

Apparently, he had discussed the issue with A.I. Shokin and F.G. Staros soon arrived at "Sputnik" for reconnaissance. In parallel with the preparation of the decree, work on the creation of a technology hybrid (in the SKB-2) and planar (in the Pulsar) integrated circuits were systematically developed.

For the final decision the situation in which would refer N.S. Khrushchev, microelectronics and demonstration of its advantages on clear was necessary to it an example. A.I. Shokin has created such situation. On 4 May of 1962 in Leningrad, the meeting with N.S. Khrushchev's participation on problems of ship construction was planned, and one of the major problems was onboard electronics. A.I. Shokin has applied all organizational experience and manager art, has involved old connection, and overlapping of the necessary events at last took place in time and space. Having arranged Khruschev's visit in SKB-2 by Staros before meeting, Alexander Ivanovich successfully used three trumps which in the given situation were directed at F.G. Staros: it KB was in Leningrad; at it was than to surprise; N.S. Khruschev was a bit attracted to F.G. Staros's since he accepted some participation in arrangement of its Russian destiny.

By the end of the 1990s in the American Russian-speaking magazine called The Problem of Eastern Europe appeared an article by M. Kuchmet titled "Participation of Americans in the Soviet microelectronics". The article affirmed that the Soviet microelectronics industry and its Center in Zelenograd's was created exclusively owing to the initiative, diligence and intelligence of two American engineers Alfred Sarant (in the USSR known as Phillip Georgievich Staros) and Joel Barr (known as Joseph Veniaminovich Berg). By 1950, they had emigrated from the USA to Czechoslovakia, and by 1955, they moved to the USSR where they headed a small 
KB in Leningrad, where they were subordinated to the GKET. This article contradicted a reality that had started numerous publications and that had distorted the historical representation of CM's creation.

Because of F.G. Starosa's roles (I.V. Berg had no independent value), we shall dwell a bit more on this story. In SKB-2 they prepared F.G. Staros's then model samples of a control computer "UM-NH" and a tiny radio receiver. They were constructed based on tiny and non-packaged elements; the senior chiefs were amazed by the small sizes. The visit was well organized. Almost month of vigorous spadework proceeded. One day prior to A.I. Shokin's visit they led a rehearsal with Staros, which should be explanatory. The visit is well daring: "UM-NH" and a radio receiver had made a necessary impression upon N.S. Khruschev. At the same place, A.I. Shokin has reported the project of the Decree on creation CM in "Sputnik" as one approved in whole by Khruschev. After intensive coordination, on 8 August of 1962, they signed the Decree of the Central Committee of the CPSU and SM of the USSR. See Figure 3.

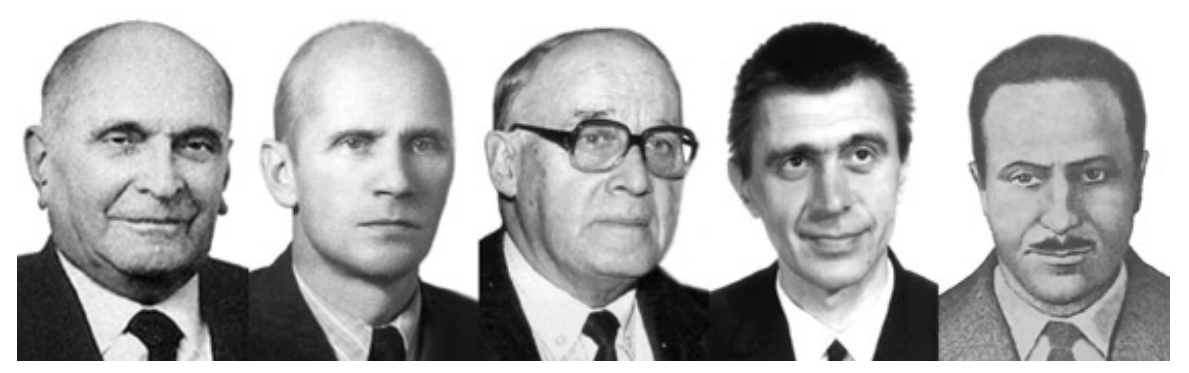

Fig. 3. Initiators creation Soviets microelectronics: Alexander Ivanovich Shokin, Feodor Viktorovich Lukin, Andrey Alexandrovich Kolosov, Boris Vladimirovich Malin, Fillip Georgievich Staros

As it is usual in similar cases, it was the conceptual Decree, the first in a turn that would follow behind. In it, they legalized that CM was to be in "Sputnik" and that henceforth, the problem of the creation and development of a homemade microelectronics plant has found the character of a national problem.

The general provisions of the concept of construction CM have been certain:

- Complex character CM with the organization of all cores of necessary scientific research institutes and experimental plants for designing and manufacturing IC is certain,

- $\mathrm{CM}$ the status of parent organization in the country on microelectronics with problems is given:

- Maintenance of designing and pilot production IC on a world technological level in interests of defense of the country and a national economy;

- Maintenance of a perspective scientific reserve;

- Development of principles of designing of the radio-electronic equipment and the computer on the basis of microelectronics, the organization of their manufacture, transfer of this experience to the corresponding organizations of the country; 
- Unification IC, conditions of their application in the equipment at the enterprises of the country;

- A professional training, including specialists of the top skills.

- Local accommodation CM in "Sputnik", where CM becomes town organize system is certain.

The Decree made certain that an initial variant of structure of the CM enterprises. It had five new scientific research institutes with three experimental plants. They included the scientific research institute of theoretical bases of microelectronics, the scientific research institute of microcircuitry, the scientific research institute of technology of microelectronics, the scientific research institute of mechanical engineering, and the scientific research institute of special materials. Additionally, they were given corresponding tasks on their creation.

It is important to note once again that the creation of $\mathrm{CM}$ was not an isolated action; it was a part of larger program of creation new branch sector - microelectronics and A.I. Shokin was its initiator and its organizer of realization. In various regions of the country (Moscow, Leningrad, Kiev, Minsk, Voronezh, Riga, Vilnius, Novosibirsk, Baku and other places) saw the beginning of alterations of available GKET enterprise or the creation of new scientific research institutes with experimental plants. In addition, serial factories with $\mathrm{KB}$ emerged for design and mass production the ICs, special materials, and technological and control-measuring equipment. Thus, CM was only a part of a huge iceberg - a main peak, but only a part of it.

It is necessary to consider as special conditions of creation and development of domestic microelectronics. The electronic industry of the countries of the Europe, the USA, Japan what remained rigid was a competition between firms as were the participants of a wide international cooperation. Our microelectronics had been completely excluded from it. The USA had created the special international seventeen-country "Coordinating Committee of East-West Trade Policy" (COCOM) that supervised all scientific, technical, trade, and economic mutual relations from the USSR. The COCOM had developed a position paper of 250 pages across Soviet progress. It was impossible to sell not only high technologies and the products belonged to area of any high technology, microelectronics, and computers, but also other technological devices such as measuring equipment, materials, and precision machines. Consequently, in the Soviet electronic industry, it was necessary to do make everything ourselves. Certainly, special services partially managed to punch a wall on COCOM surrounding us and in a roundabout way to extract some products, documentation, materials, and equipment. However, all that was extracted was in scanty quantities and only to look and feel. It was necessary to design all this and to duplicate it in sufficient volume. Sometimes, the received samples were copied, but an exact copy to make it was impossible because of differences in materials, technologies, and equipment. Sometimes they did functional analogues; sometimes they completely did their own development. Nevertheless, they always developed and duplicated everything themselves.

\section{The Center of Microelectronics}

Soon after the release of the Decree, A.I. Shokin's command had started the creation of the CM (later the Centre of science - NC). The CM Decree had been given the 
right to employ specialists from any part of the USSR. Professionals and a scientific reserve in microelectronics, owing to the preliminary actions of A.I. Shokin, F.V. Lukin, and A.A. Kolosov who were already available in the country at the moment of signing of the Decree.

The formation of scientific research institute with experimental plants had begun. In 1962 began the scientific research institute of microdevices (NII MP) with a factory "Component" and Scientific research institute of precise machine building (NII TM) with "Elion". In 1963 began the scientific research institute of precise technologies (NII TT) with "Angstrem" and the scientific research institute of materiology (NII MV) with "Elma". In 1964 began the scientific research institute of molecular electronics (NII ME) with "Micron" and the scientific research institute of physical problems (NII FP). In 1965 began the Moscow institute of electronic technics (MIET) with "Proton" (in 1972). In 1968 began the central bureau on application of integrated microcircuits (CBPIMS). In 1969 began the specialized computer center (SVC) with "Logic" (in 1975). By the beginning of 1971 at NC in Zelenograd 12.8 thousand people were working. In 1976 based on the NC the country created the "Centre of science" with thirty-nine enterprises in different cities of the country that employed almost eighty thousand people.

The uniform organization at CM was not repeated; its enterprises submitted to the fourth central board of the GKET. The first had been organized by NII MP and NII TM. The appointed directors were I.N. Bukreev and E.H. Ivanov typed experts and organized work of scientific research institute while on the time premises. Workers of the Central board and GKET helped them. F.G. Staros also helped in part. Here is the recollection of I.N. Bukreev:

"Staros actively helped me. Specialists of NII MT trained at it in Leningrad. Besides in 1963 it had transferred us four designed it $K B$ vacuum disposition system for mark thin-film (the first in the country). We at once began to master technology, and owing to it to 1964, there were the first microelectronic products. And if waited, while will construct our institute of mechanical engineering, we would lose two to three years".

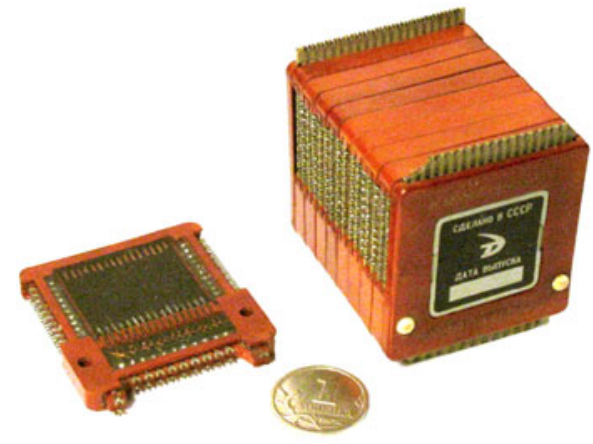

Fig. 4. "Cub-2" - The module RON in capacity of 16 19-digit words, "Cub-2" in capacity of 128 19-digit words, Between them a coin 1 copeck 2003) The size of the module $32 \times 34 \times 4,125 \mathrm{~mm}$. The size of the block: $128 \times 19$ bats $-32 \times 34 \times 42 \mathrm{~mm} \mathrm{256 \times 19}$ bats $32 \times 34 \times 42 \mathrm{~mm}$ Such a Cub flied around of the Moon

F.G. Staros with CM shared both the ideas and a reserve. In NII MP, the idea of the micro-receiver was already based on microelectronic technology and it had been realized anew. Angstrem issued products designed in Leningrad such as the block of memory on ferrite plates with many openings of a "Cub-2", shown in Figure 4. In NII TT, the idea was more technological; a reliable variant of "Cub-3" was creatively 
advanced and designed. Probably, there were also other examples. F.G. Staros had really brought a certain contribution to the preparation of the creation of $\mathrm{NC}$. He was one of the active members of the large command and this command stood at the forefront, though not the first.

On 29 January of 1963, the vice-president of the GKET approached F.V. Lukin and on 8 February of 1963, he became director of CM. Its deputy for science had appointed F.G. Staros, still remaining the chief at the Leningrad KB. However, F.G. Staros had ambitions and plans for the post of director of CM. Not having received his expected appointment, he had taken offence and had actually withdrawn from performance of functions of the deputy director. This caused harm to that business on which the organization had placed many forces. I.N. Bukreev tells about it in the following:

"The joke is recollected: "Have decided to collect those who on the first Saturday carrying a log from V.I. Lenin. Five thousand persons had responded nearby. Actually, there were only five. The same occurs now: many, “close known” Staros's, tell pull the long bow about its invaluable contribution to becoming Zelenograd microelectronics, initiating unhealthy interest to the person of this man. ... Itself Staros in Zelenograd never worked. I to it equipped a cabinet in "boarding school" (in 1-st microdistrict). But there was it here only 3-4 times at some o'clock. ... Actually, there was Staros in Zelenograd only till the summer a 1963. During this period from the first directors to it I contacted only. ... Lukin becomes director of a under construction Center of microelectronics and Staros's appoint it deputy on a science. ... Certainly, it wished to supervise over the Center. Well, does not happen. After purpose Lukin it more here did not appear."

Director of NII TT of V.S. Sergeev is even more categorical:

"About Staros and Berg. I revolted when they named "father" of microelectronics and Zelenograd. From the point of view of techniques, their influence was zero. By the way, in America Staros in microelectronics was not engaged."

These are direct certificates of two direct participants of theevents, the first directors of the first undertakings. One should not forget that Alfred Sarrant (in the USSR - F.G. Staros) stopped working as an electrical engineer in 1946, i.e. a year beforecreation of the first transistor in 1947 (the first informationabout it appeared in 1948), and in 1950 (before creation of the firstintegrated circuit in 1958) left the USA emigrating to Europe.

The heads created CM present on work just not twenty-four hours straight. Their drivers, who are not maintaining such mode of work that varied with frightening frequency. In reality, F.G. Staros's busy season happened in Zelenograd where he ignored weekly conferences. That is, in the fray of heavy daily work to creation the electronic industry, which demanded not only knowledge but also selflessness, he practically never participated. As a result, in 1964 there is an order on removing F.G. Staros's from the deputy director position at CM. Figure 5 shows the founders of the center. 


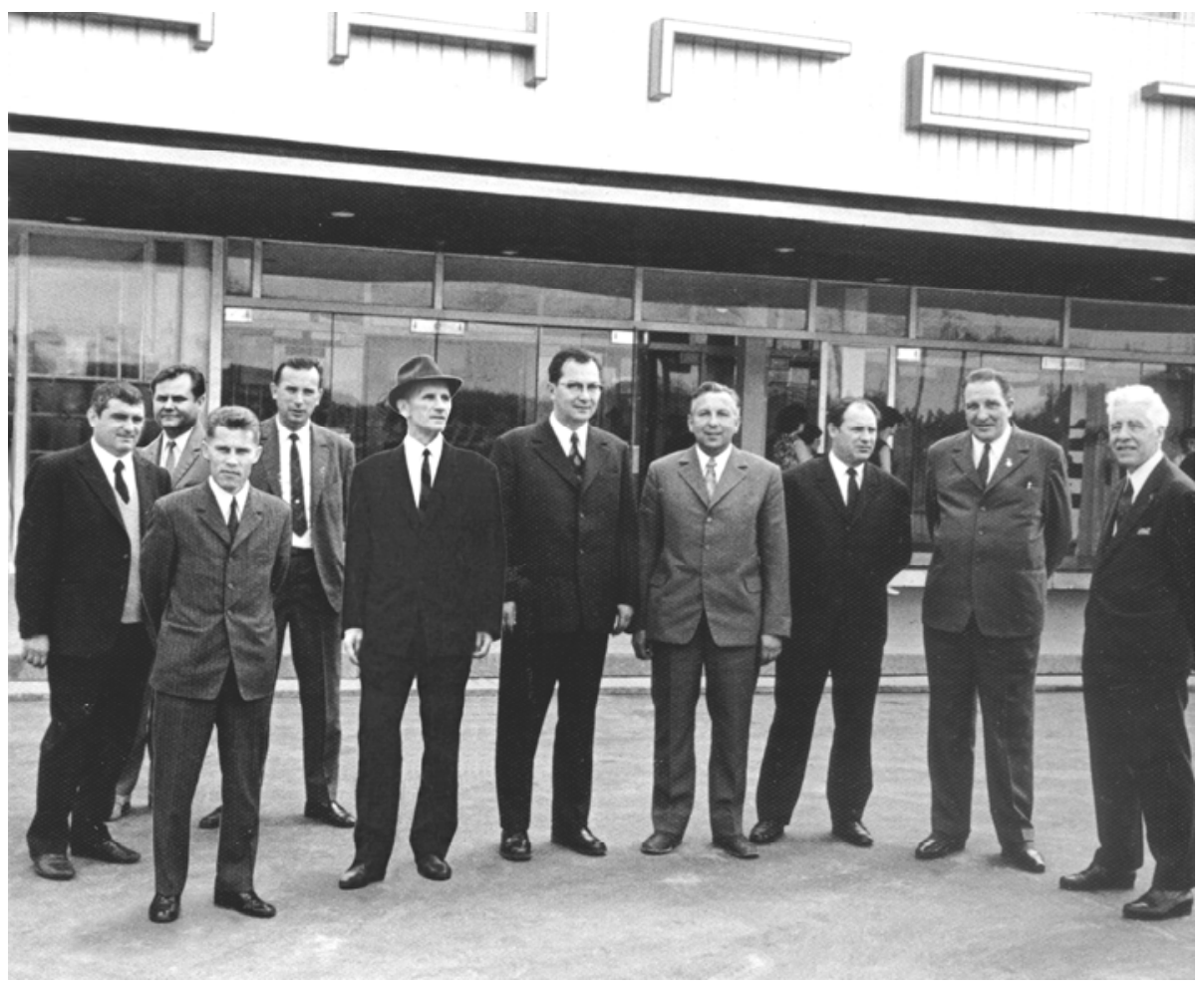

Fig. 5. Founders of the Center of microelectronics in Zelenograd at an input in NII TT and a factory «Angstrem». From left to right: L.S. Garba (director of «Elma» at NII MV), B.V. Tarabrin (director of CB PIMS), K.A. Valiev (director of NII ME), A.J. Malinin (director of NII MV), V.F. Lukin (director HЦ), D.I. Juditsky (director SVC), A.K. Katman (chief engineer of NII TT), V.V. Savin (director of NII TM), G.V. Bechin (director of «Angstrem» at NII TT), V.S. Sergeev (director of NII TT).

\section{The First Results}

Soon, CM had started the creation of essential new production. In May of 1963 at NII TM they designed the first samples of vacuum deposition equipment. In the second half of 1963 at NII MP, the first results on thin-film technology were already developed and they designed the radio receiver «Micro». Its first model was the direct strengthening receiver and the second was the superhetrodyne. In 1964 when I.N. Bukreev brought this receiver to the USA at the congress of radio engineers, it made a world sensation! Photos and statements appeared in newspapers: How could the USSR overtake us? The «Micro» was sold for currency in France and England. Khruschev took them with himself abroad as souvenirs and gave them to G. Nasser and Queen Elizabeth.

The radio receiver «Micro» (Figure 6) used thin-film technology; it was first time in the country that they used batch production of microelectronics. In the second half of 1963 in NII MP the receiver was designed and its batch production began in 1964 
at Angstrem's, where eighty thousand pieces were transferred to the MRP serial factory in Minsk. Up to the middle of the 1970s, one could buy this microreceiver in shops of the USSR and France.
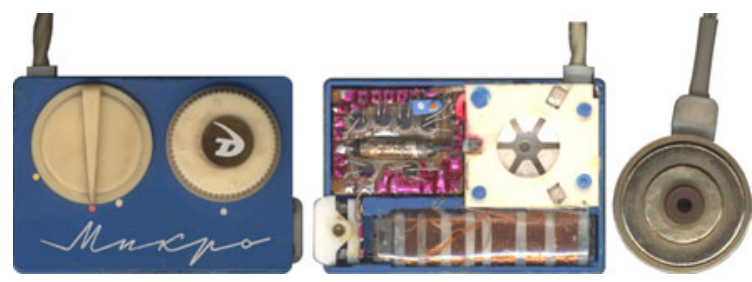

M 1:1 M 2:1

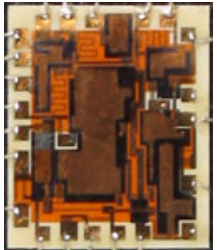

Fig. 6. The product of microelectronics first in the USSR - radio receiver «Micro» It is produced on the basis of thin-film hybrid technology, a thin-film payment on a photo on the right with double increase. The size of the receiver $43 \times 30 \times 7,5 \mathrm{~mm}$ (without acting controls). The broadcast through phone for a hearing aid, inserted in an ear (the third at the left) was listened.

By 1964, NII TT started developing a series of thick-film HIC "Tropa"; its designer was A.K. Katman. Technical materials and literature in this area did not exist; there were only photos of the microcircuits that were issued by the firm IBM. All work began with nothing. They designed everything: the circuitry, the constructions, materials, technologies, and equipment.

By 1965 in Zelenograd, the Micron had begun to release the first semiconductor IC "Irtysh", designed by A.P. Golubev in NII ME based on the planar technology created in the Pulsar and put on the Micron. See Figures 7 and 8.
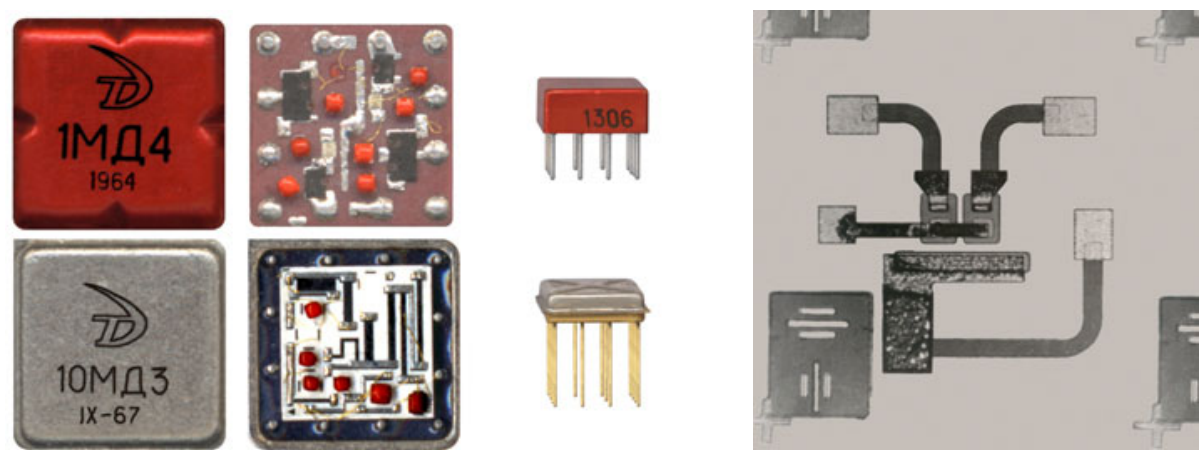

Fig. 7. First series IC in the USSR, "Tropa", thick-film, a top number, "Posol", thin-film, the bottom number. (At the left and in the center - in the double size, on the right - in full size).

Fig. 8. The first in CM semiconductor IC "Irtysh". Photo of topology of a crystal.

In 1966, Elma already issued fifteen kinds of the special materials designed in NII MV, and Elion produced twenty types of the technological devices in NII TM technological, control, and measuring equipment. In 1969, Angstrem and Micron 
already issued more than two hundred types ICs, and by 1975 in NC, they designed 1020 types ICs. They transferred all this to serial factories. This was only the beginning.

The results of many years of NC work did not look bad at a level of world microelectronics. Its first product - radio receiver «Micro», already had no equal the world. The first hybrid IC corresponded to a world level. By the way, the first-ever IC, flown the Moon (in 1969) and returned to the Earth, were Angstrem's "Tropas". In semiconductor IC, the USSR noticeably lagged behind, but would soon catch up with world leaders. In the 1970s, the most successful semiconductor company in the world was Intel. Intel issued the dynamic RAM in a capacity of 4K bits in 1974 and Angstrem issued the same in 1975. Accordingly, it issued 16K bits in 1977 and in the beginning of 1978; in 1979 both firms have issued on the market 64K-bit modules practically simultaneously. The similar situation existed at NII ME. In the beginning of the 1970s, the director of NII ME, K.A.Valiev, went to the USA to Motorola to show them the IC series 500 (analogous to the MC10000). Having investigated samples, experts of firm ascertained, that at identity of topology, IC series 500 had a higher speed than their designs and they were compelled to ascertain that the USSR technology was better. There are a number of other similar examples. See Figure 9.

The culmination of this competition began in 1979 when at NII TT they designed a single-crystal 16-digit computer, K1801VE1, with an "Electronics NC" architecture (in present terminology - the microcontroller). According to conclusion of the State Commission inspecting the project at that time, a computer of such level (with a 16-bit arithmetic-logical unit) did not have foreign analogues. As a whole during the period from 1964 to 1980 , the backlog of development at $\mathrm{NC}$ on various types of IC comparisons with the maximum world achievements changed between zero and three years. Sometimes they pulled forward. Nevertheless, approximately the same dynamics existed and at leading foreign firms, they lagged behind their competitors and then advanced them a little. That is, it is possible to confirm that development of microelectronics at the NC in Zelenograd as a whole corresponded to a world level during those years.

However, regarding the volume of production of integrated circuits, the branch

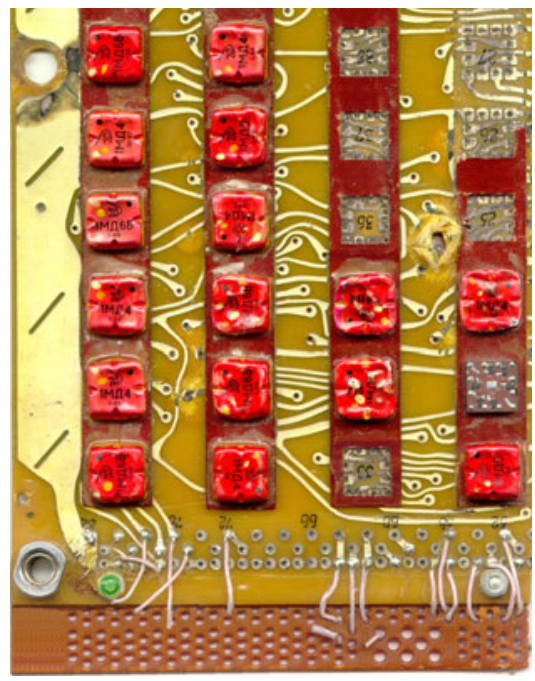

Fig. 9. IC “Tropa” first-ever send in 1969 in a free space, have flown about the Moon and have returned to the Earth. Fragment of a board of computer "Argon". Part IC is dismantled for research of results of long influence on them of a free space. as a whole lagged considerably behind the foreign level; the means did not suffice for the development of capacities of serial factories (and they in microelectronics were very dear) in the country. As a result, the loading on the experimental NC plants had sharply increased, specifically by a batch 
production of integrated circuits. This was the beginning of a fatal decline; it affected the further prospects of developing microelectronics. Opportunities to improve experimental plants for new materials, processes, technological routes, equipment, and products became sharply limited. Because of this and a number of other reasons, by approximately 1980 the progressing backlog of the Soviet microelectronics compared to a foreign level had begun. The rest is history. 